\title{
Arte pós-violência no Peru: as experiências do Colectivo Sociedad Civil e de Yuyachkani
}

Art post-violence in Peru: the experiences of Colectivo Sociedad Civil and Yuyachkani

Flávia Almeida Vieira Resende ${ }^{1}$ 


\section{Resumo}

Neste artigo nos questionamos sobre a arte realizada em tempos de violência e pós-violência, no contexto do Peru no final do conflito armado interno (1980-2000). O que pode a obra de arte em contextos de violência extrema? $O$ que podem esses contextos sobre as obras de arte? Pode a obra de arte resistir - e existir? Trabalhamos sobre as performances do Colectivo Sociedad Civil Lava la bandera (2000) e Pon la basura en la basura (2000), e o teatro do grupo Yuyachkani nas peças Adiós Ayacucho (1990), Antígona (2000) e Sin título - técnica mi$x$ ta (2004). Nesse contexto, interessamnos as ideias de efetividade e papel da obra de arte, performance, ativismo político e arte e memória.

Palavras-chave: Conflito armado interno no Peru; Arte e violência; Performances políticas; Teatro político

\section{Abstract}

In this article, we question the art performed in times of violence and post-violence in Peruvian context at the end of the internal armed conflict (1980-2000). What can the work of art in extreme violence contexts express? What can these contexts on the artworks express? Can the artwork resist - and exist? We work on the performances of Colectivo Sociedad Civil, Lava la bandera (2000) and Pon la basura en la basura (2000), and on the Yuyachkani Theater in the plays Adiós Ayacucho (1990), Antigona (2000) and Sin título - técnica mixta (2004). In this context, we are interested in the ideas of effectiveness and the role of the artwork, performance and political activism and art and memory.

Keywords: Peruvian internal armed conflict; Art and violence; Political performances; Political theater 
Após um contexto de violência extrema, a obra de arte ainda pode existir? E, se sim, pode ela resistir, ser uma obra de "resistência"? A relação entre arte e política, especialmente em contextos marcados por uma violência e uma opressão extremas, parece nos apresentar mais perguntas que respostas. Estas, quando aparecem, não servem como modelo, mas como direcionamentos provisórios e talvez localizados em um contexto específico. Ou, podemos precisar: não servem como modelo, mas servem, talvez, como uma esperança, como os pequenos vaga-lumes de Didi-Huberman (2011).

Essas perguntas iniciais, porém, parecem ter uma resposta, em certo sentido, óbvia. Já estamos a mais de 70 anos de Auschwitz e as obras de arte continuam existindo e, de uma forma mais ou menos "efetiva", resistindo. Porém essas perguntas nos oferecem uma provocação, um convite a pensar essa obra de arte pós-violência em sua [necessária?] relação com tais contextos. Nesse sentido, poderíamos já acrescentar outras questões: qual é a obra de arte que sobrevive a um contexto de violência? Em que medida e de que forma ela relaciona-se com o real? A obra de arte tem um papel, como uma espécie de "dever a cumprir" frente a essa realidade? $E$, nesse sentido, é produtivo pensar em uma "efetividade" da obra frente a esses contextos? Finalmente: o que pode a obra de arte nesses contextos? Ou ainda: o que podem esses contextos sobre as obras de arte? Pode a obra de arte resistir - e existir?

Propomo-nos a pensar essas questões a partir do contexto de violência instaurado pelos vinte anos de conflito armado interno no Peru, entre as décadas de 1980 e 2000. Em 17 de maio de 1980, na véspera da primeira eleição após doze anos de governos ditatoriais militares no Peru, um grupo maoísta do Partido Comunista do Peru, conhecido como Sendero Luminoso, liderado por Abimael Guzmán, realiza seu primeiro ato terrorista: a queima de urnas e cédulas de votação em Chuschi, distrito de Cangallo, em Ayacucho. Embora não seja o início da história de violência e desigualdades no país, essa data pode ser considerada um marco para tudo o que viria a se passar em seguida: violações de direitos humanos, opressão e violência contra os povos mais fragilizados do país; reações desproporcionais e injustificáveis por parte do governo e das forças armadas; o acirramento das diferenças étnicas e sociais já presentes entre a população.

Ao final do conflito, a Comissión de Verdad y Reconciliación do Peru - CVR-Peru registrou cerca de 69 mil vítimas, entre mortos e desaparecidos, dos quais três a cada quatro eram campesinos ou campesinas cuja língua materna era o quéchua (Peru, 2003). Esses números reforçam a ideia de que a violência perpetrada, tanto por parte do Sendero Luminoso quanto por parte das Forças Armadas, tinha um alvo prioritário, que era justamente as populações mais pobres e mais distantes - cultural e geograficamente - da capital Lima.

Vale mencionar aqui que boa parte da efetividade do projeto do Sendero Luminoso deve-se a uma série de ações no campo do simbólico. Para fazer referência a apenas algumas, temos a mitificação criada em torno da figura do líder, o já citado Abimael Guzmán, conhecido como capitão Gonzalo e tido como o quarto braço do comunismo - ao lado de Marx, Lenin e Mao. Além disso, conforme nos apresenta Victor Vich, no livro El canibal es el outro, alguns pontos do discurso do Sendero Luminoso contribuem para a disseminação da ideologia do grupo, principalmente nas 
zonas rurais andinas. São eles: a visão teleológica da história; a dissolução do sujeito dentro dos objetivos do partido; o culto à morte; e o discurso pedagógico. Todos esses pontos são propagados, principalmente, por meio do discurso, com uma retórica de convencimento, a fim de criar e incutir uma ideia messiânica de uma identidade não mais nacional, mas global e a-histórica, ou seja, não vinculada à realidade local, mas como um projeto apartado da história concreta. É interessante pensar que é justamente em Ayacucho, um dos departamentos mais pobres do país naquele momento, que floresce tal ideologia, no seio da Universidad Nacional de San Cristóbal de Huamanga. Numa mescla entre a pobreza intensa, os arcaísmos presentes em uma sociedade rural e o pensamento intelectual proporcionado pela Universidade que boa parte da população compra o discurso messiânico dos senderistas e passa a seguir e reverenciar o líder "capitão Gonzalo", mesmo em detrimento da própria vida e dos direitos humanos.

É importante ressaltar, no entanto, que, embora o Sendero tenha sido o catalizador do conflito armado interno, como conclui o Informe final da CVR-Peru, boa parte das ações de violência perpetradas no período foi realizada pelas Forças Armadas do país, em momentos em que estavam no poder governos democráticos. Numa atuação de violência sem precedentes na história da instituição, mesmo em governos ditatoriais, as Forças Armadas foram resposáveis por violações sistemáticas dos direitos humanos (e não excepcionais). Assim, como afirma a CVR-Peru, "a emergência excepcional se torna normalidade permanente; o abuso massivo se converte em excesso; a inocência acarreta o cárcere; a morte, finalmente, se confunde com a paz"3 (Peru, 2003, p. 6). O estado de exceção estabelecido em diversas zonas do Peru acaba por se configurar em um estado permanente de exceção: "uma vez controlada a ameaça subversiva armada, as populações ficaram sob domínio militar por extensos períodos" ${ }^{4}$ (Peru, 2003, p.11).

Para que isso ocorresse, houve em boa parte uma concordância - ativa ou passiva - de uma parcela da população peruana, especialmente da população limenha, para quem o conflito parecia suficientemente distante. Isso foi possível, também, por questões simbólicas, que permitiram a construção de uma imagem do Outro - o andino, o falante de quéchua, homem, jovem - que o convertia na categoria - hoje tão significativa e ao mesmo tempo problemática - do terrorista, daquele que, em última instância, é passível de ser eliminado sem que haja qualquer implicação legal nisso (uma espécie de homo sacer, na terminologia de Agamben, 2010). Não custa lembrar que a maioria das ações que objetivam a segurança nacional (dentre elas a instauração do problemático estado de exceção) são pautadas por uma ideia de necessidade, possibilitada, sobretudo, pela disseminação do medo. Mais do que conceitos objetivos, essas ideias pairam sobre o campo das subjetividades e das sensibilidades.

Nesse contexto, como afirma Victor Vich (2015, p. 14-15), "a produção simbólica acompanhou o período da violência desde seus inícios e se constituiu em um agente

\footnotetext{
2 Também a guerrilha Movimento Revolucionário Tupac Amaru - MRTA, a partir de sua fundação em 1984, foi responsável por ações de violência, porém os principais agentes nas duas décadas de conflito foram o Sendero Luminoso e as Forças Armadas.

3 "La emergencia excepcional se vuelve normalidad permanente; el abuso masivo se convierte en exceso; la inocencia acarrea la cárcel; la muerte, finalmente, se confunde con la paz." Esta e as demais traduções deste artigo são da própria autora.

4 "Una vez controlada la amenaza subversiva armada, las poblaciones quedaron bajo dominio militar por extensos períodos".
} 
chave na opção de compreender (e denunciar) o que estava acontecendo"5, e ainda continua "cumprindo um papel protagônico no intento de instalar um novo imaginário nacional a partir da desestabilização dos sentidos comuns existentes" ${ }^{\prime 6}$. A arte, portanto, cumpre aí um papel de atuação frente a esse contexto: o de compreender e denunciar os acontecimentos e o de construir um novo imaginário por meio do dissenso. Com isso, não entendemos e nem queremos afirmar que a obra de arte tenha necessariamente um "dever a cumprir" frente a contextos de violência. Mas talvez possamos entender que ela cumpre, muitas vezes, tal papel porque, como afirma Rancière, estética e política têm fundamentos comuns: "posições e movimentos dos corpos, funções da palavra, repartições do visível e do invisível" (Rancière, 2009, p. 26).

A forma de organização do Sendero Luminoso é também uma maneira de distribuição de lugares nessa partilha, ao estabelecer a posição simbólica do líder Abimael Guzmán (inclusive em relação a um imaginário já prévio do comunismo mundial) e diminuir o papel das subjetividades de seus seguidores. Assim, uma atuação no campo do simbólico é uma atuação no campo do político, no sentido de desestabilizar formas de visibilidade e maneiras de fazer e de ser, de atuar e de compreender o mundo, de dar voz, de permitir falar. E é somente neste sentido que elas podem ser lidas em sua "efetividade": não com consequências concretas de mais ou menos êxito, mas com a sua capacidade de propor novas formas de partilha do sensivel (Rancière, 2009).

Gostaríamos de trazer aqui alguns exemplos dessas produções simbólicas realizadas durante ou logo após o período de violência no Peru, para que possamos buscar nelas não modelos, como dissemos anteriormente, mas formas de sobrevivência. Para os primeiros exemplos, partimos principalmente da leitura de Victor Vich em Poéticas del duelo, especificamente no capítulo intitulado "Desobediencia simbólica: performance y participación política al final de la dictadura fujimorista". Esse capítulo inicia-se com uma epígrafe de Adorno, que afirma que "as obras que hoje contam são aquelas que já não são obras". Interessante provocação para pensarmos que tipo de obra de arte é possível após um contexto de violência extrema; não mais uma obra fechada em si mesma ou em seu regime mimético, mas capaz de borrar fronteiras, de fazer-se ela mesma realidade e de incorporar o real que antes the chegava por meio da mimese; uma obra que abarque o testemunho e as vozes dissonantes, as vozes sem lugar em um regime político; uma arte que seja resistência por sua própria existência, pelo seu colocar-se em um espaço-tempo em que não the era permitido estar. Algo como o que Rancière define como o "regime estético das artes":

Aquele que propriamente identifica a arte no singular e desobriga essa arte de toda e qualquer regra específica, de toda hierarquia de temas, gêneros e artes. [...] Ele afirma a absoluta singularidade da arte e destrói ao mesmo tempo todo critério pragmático dessa singularidade. Funda, a uma só vez, a autonomia da arte e a identidade de suas formas com as formas pelas quais a vida se forma a si mesma. (Rancière, 2009, p. 33-34)

Embora Rancière aqui não esteja se referindo especificamente à arte pós-violência, ou mesmo à arte de vanguarda, o que ele afirma fazer parte desse regime estético é justamente aquela arte capaz de borrar as fronteiras do espaço que the

\footnotetext{
5 "La producción simbólica acompañó al período de la violencia desde sus inicios y se constituyó en un agente clave en la opción de comprender (y denunciar) lo que estaba sucediendo".
}

6 "Cumpliendo un rol protagónico en el intento por instalar un nuevo imaginario nacional a partir de la desestabilización de los sentidos comunes existentes" 
era destinado na sociedade e retrabalhar a partilha do sensível. Os exemplos que aqui trazemos têm em comum o fato de estarem sob o [vasto] campo daquilo que entendemos como performance. Como afirma Vich (2015, p. 162), "as performances tornam visível a estrutura de um poder que se deixou de ver e permitem observar as possibilidades de agência dos sujeitos e os espaços vazios que a hegemonia ainda não pôde conquistar"7.

É nesse sentido que Lava la bandera insere-se no espaço público no ano de 2000, para articular e mobilizar uma sociedade que a muito custo começava a questionar as estruturas de poder, mas que ainda estava paralisada pelo medo (principalmente do terrorismo senderista). Essa ação, proposta pelo Colectivo Sociedad Civil, era simples: reunir-se na praça principal de Lima, com bacias de água e sabão Bolívar ${ }^{8}$, para lavar a bandeira do Peru e depois estendê-la em grandes varais, fazendo do espaço público um enorme "quintal coletivo" (Dieguez Caballero, 2011). Uma conexão da "vida cotidiana e da vida política" (Vich, 2015, p. 172) que ganhou inúmeros adeptos na capital e mesmo no interior do país.

Nas palavras de Gustavo Buntinx (2006), um dos fundadores do Coletivo, "a luta pelo poder simbólico no próprio espaço público permitiu a reconstrução dessa autoestima cidadã que a ditadura pretendia submeter generalizando na população certa síndrome de pós-guerra (civil)" 9 . É pelo símbolo da bandeira nacional que a população peruana se une, assumindo uma identidade nacional e um desejo comum: lavar a pátria da corrupção que assola o país e de toda a violência presente nos últimos anos. Como analisa Vich (2015, p. 172), "Lava la bandera demonstrou que o Estado-nacional segue sendo um marco fundamental na definição das identidades sociais e que a construção do cidadão se encontra inevitavelmente atravessada pelo simbólico e pelo político"10.

O caráter artístico da ocupação acaba por se mesclar ao caráter político. Como afirma Buntinx (2008), trata-se de "uma experiência artística que se socializa radicalmente até renunciar a sua própria especificidade artística"11. Isso porque a ação ganha um caráter prioritariamente social de luta simbólica pela derrubada - cultural, inclusive - do regime de Fujimori. É interessante aqui a percepção de Buntinx sobre o caráter artístico da intervenção: ele estava presente no início, talvez na ideia inicial, mas se dissolve na atitude política do desenvolvimento da ação. O que permanece presente é o caráter simbólico da performance/ação política.

Já a performance Pon la basura en la basura, também organizada pelo Colectivo Sociedad Civil no mesmo ano de 2000, realiza sua interferência não na esfera pública, mas nas casas de políticos importantes ligados ao governo de Fujimori e em locais emblemáticos do regime (emissoras de televisão, o Comando das Forças Armadas), numa espécie de "escrache". À maneira das ações que ficaram conhecidas, sobre-

\footnotetext{
7 "las performances vuelven visible la estructura de un poder que ha dejado de verse y permiten observar las posibilidades de agencia de los sujetos y los espacios vacíos que la hegemonía no ha podido aún conquistar".

${ }^{8}$ É significativo que o grupo tenha proposto justamente o uso do sabão Bolívar. Embora seja um sabão muito usado no Peru, e só isso já bastaria para justificar a escolha, o fato de ele se chamar Bolívar, nome de um dos principais líderes da independência da América Hispânica, dá uma nova nuance à performance. É possível entender a lavagem da bandeira também como um novo ato de proclamação de independência e de integração com a América Latina.

9 "La lucha por el poder simbólico en el propio espacio público permitió la reconstrucción de esa auto-estima ciudadana que la dictadura pretendía someter gene

10 "Lava la bandera demostró que el Estado-nacional sigue siendo un marco fundamental en la definición de las identidades sociales y que la construcción del ciudadano se encuentra inevitablemente atravesada por lo simbólico y por lo político."

11 "Una experiencia artística que se socializa radicalmente hasta renunciar a su propia especificidad artística".
} 
tudo, na Argentina, os escraches se configuram como atos de denúncia a pessoas acusadas de violação aos direitos humanos ou corrupção. Trata-se de uma denúncia realizada em frente à casa ou local de trabalho dos acusados, com ações como pichações, cantos, gritos, de forma a tornar públicos os atos cometidos por aquela pessoa.

No caso de Pon la basura en la basura, a ação consistia em jogar nos locais escolhidos sacos de lixo preto impressos com fotos de Fujimori e Montesinos com trajes de presidiários ${ }^{12}$. Era um momento em que o esquema de corrupção do governo vinha à tona, logo após o vazamento dos primeiros vladvideos ${ }^{13}$, e Fujimori, por fax enviado do exterior, renunciava ao cargo de presidente do Peru. A força da performance, se quisermos falar de sua efetividade, consistia em, a partir do simbólico, exercer uma pressão social em um momento fundamental de transição política. Como assinala Vich (2015), o escracho realizado na casa do vice-presidente Arnaldo Marquez demonstrou a insatisfação pública com a possibilidade de que ele assumisse a presidência. A ação do Coletivo foi um dos fatores que exerceu pressão para que Marquez, no dia seguinte, renunciasse ao cargo.

Diferentemente dos exemplos de que trataremos a seguir, das peças de Yuyachkani, essas duas performances não se inserem claramente em um campo da arte, constituindo-se mais como ativismo político, como ações simbólicas que interferem nas maneiras de configuração e de apreensão do real, do contexto histórico. Gustavo Buntinx evidencia isso ao afirmar que "com esses rituais não queríamos entrar para a história da arte; simplesmente queríamos mudar algo da história 'a secas'."14 (apud Vich, 2015, p. 183). Com esse pensamento também não propunham uma relação entre "artistas" e "espectadores", mas transformavam a todos em atores do processo simbólico e social.

Já o grupo de teatro Yuyachkani insere-se, a princípio, nessa categoria milenar da arte que é o teatro, muito embora diversas de suas ações pertençam a um território híbrido em que também comungam performance e ativismo político. Talvez aqui devamos voltar à postulação de Adorno para nos questionarmos sobre essa dificuldade de classificação de certas manifestações estéticas/políticas. Acreditamos, nesse sentido, que mesmo as "obras" de Yuyachkani que são mais fechadas e cujo texto dramatúrgico está escrito e publicado, e até mesmo aquelas que possuem inspirações em obras literárias (como é o caso de Adiós Ayacucho e de Antígona), permanecem como um espaço aberto, maleável e de difícil classificação. Talvez a maior precisão conceitual tenha se encontrado em Sin título - técnica mixta, peça estreada em 2004. Mesmo aí, figura um vocabulário das artes plásticas, que já antecipa uma ideia de que a obra seria uma espécie de performance/instalação. Esbarramos aqui no problema da utilização de conceitos ocidentais para classificar manifestações que se aproximam da cultura andina, cujas relações entre arte e vida, atores e espectadores, presença e representação são bem diferentes da maneira como costumamos entender.

\footnotetext{
${ }^{12} \mathrm{O}$ Coletivo Sociedade Civil distribuiu mais de 300 mil sacos de lixo para essas ações. Esses sacos eram enchidos não de lixo, mas de jornal ou apenas de ar. ${ }^{13}$ Os vladvideos eram filmagens feitas pelo próprio Vladmir Montesinos, principal assessor de Fujimori, em que este aparecia efetuando esquemas de corrupção. 0 vazamento dos vídeos escancarou tais esquemas para a população no momento em que Fujimori entraria para o seu terceiro mandato.

14 "con esos rituales no queríamos ingresar a la historia del arte; simplemente queríamos cambiar algo de la historia a secas."
} 
De toda forma, essas três obras mencionadas apresentam maneiras distintas de lidar com o período de violência, e é isso que gostaríamos de destacar aqui. Adiós Ayacucho, estreada em 1990, é baseada na novela homônima de Julio Ortega, em que um campesino assassinado pela polícia em Ayacucho viaja a Lima para recuperar o restante de sua ossada e entregar uma carta de denúncia ao presidente Belaúnde. Na peça, a corporificação do morto Alfonso Cánepa se dá pela figura de um Q'olla, um personagem dançante das festas populares andinas. É por meio do humor presente na alternância das vozes do morto e do dançante no corpo do ator Augusto Casafranca que o Yuyachkani busca lidar com uma violência tão explícita e concreta como era aquela da década de 1990 no Peru.

Antígona, estreada em 2000, com dramaturgia do poeta José Watanabe, é baseada no texto clássico de Sófocles. Porém, na versão de Yuyachkani, a peça transforma-se em um solo, no qual a Narradora/Ismene propõe-se a dar corpo e voz aos personagens daquela história, e relembrá-los a cada noite, como uma forma de redimir-se pelas ações que não pôde fazer a tempo. Trata-se dos momentos finais do conflito armado interno, mas quando o governo de Fujimori ainda pleiteava o seu terceiro mandato. A peça proporciona uma identificação por parte do público peruano, todo ele de alguma forma envolvido - ainda que com sua passividade - no período de violência, e faz um convite ao trabalho de memória. Por meio de uma história da mitologia clássica, e sem atualizar o tempo ou o local em que se passa a história, Yuyachkani fala de seu próprio contexto.

Ambas as peças - Adiós Ayacucho e Antígona - fizeram parte do projeto "Nunca más", da CVR-Peru, apresentando-se nas comunidades em que ocorreriam as audiências públicas da Comissão. Ali, as histórias de Cánepa e Antígona se misturavam às histórias reais de violência presente entre a população andina; tornavam-se portavoz, espaço de reflexão, convite ao testemunho público. Como afirma Miguel Rubio Zapata (2006, p. 61), diretor do grupo, "durante todo esse tempo sentimos como pareciam apagar-se as fronteiras entre a realidade social e a de nossos personagens"15. Ambas as peças trazem imagens de rituais de sepultamento e tratam da dificuldade de realizá-los - seja pela ausência do corpo, seja pelo impedimento oficial de se velar um traidor. Ambas apresentam-se como estruturas fechadas, nas quais o espectador é convidado a participar com seu olhar e identificação. Constituíam, assim, aquilo que Ileana Dieguez Caballero (2011, p. 74) denomina uma "communitas xamânica", "em uma experiência que propiciava um caminho de restaurações simbólicas", a fim de que o público pudesse realizar, simbolicamente, o necessário luto.

Finalmente, Sin título - técnica mixta, peça estreada em 2004, quatro anos após o término do conflito e um ano após a entrega do relatório final da CVR-Peru, instaura-se como um "museu da memória". Recortes de jornal, fotografias, roupas, carteiras de sala de aula estão colocadas ao lado de figuras/personagens/performers representativos não só do período de violência, como também da guerra contra o Chile e da história peruana de forma geral. Nesta peça, o público é convidado a transitar pelo espaço, encontrar seus próprios pontos de foco, descobrir detalhes e construir suas próprias leituras sobre aquela profusão de fragmentos vivos de história. A

15 "Durante todo este tiempo hemos sentido cómo parecían borrarse las fronteras entre la realidad social y la de nuestros personajes". 
memória inscrita no corpo dos atores transforma-os em espécies de estátuas vivas nesse "museu da memória", em receptáculos e transmissores de uma experiência de violência que foi perpetrada contra outros corpos; transforma-os, enfim, em testemunhas. Nesse sentido, nas palavras de Ileana Dieguez (2012, p. 05),

o corpo como suporte e instrumento de ação para a prática estética que torna visíveis os corpos ausentes de um ethos coletivo constitui-se numa prática política que incide na rearticulação simbólica da memória, que sufoca e deforma as políticas de silenciamento.

Uma vez mais, o que está em jogo é a rearticulação de um espaço simbólico que havia sido desarticulado pela experiência da violência e da violação aos direitos humanos. No caso de Sin título, interessa ao grupo não exatamente a denúncia de ações que estão acontecendo, mas o desejo de realizar na arte uma evocação da memória coletiva, tornar o teatro um espaço privilegiado na "luta de memórias" (Jelin, 2012), em que é possível fornecer diversos elementos para que o público construa sua narrativa da História oficial.

Se quisermos ensaiar uma resposta a algumas das questões propostas no início deste artigo, podemos afirmar que esses contextos podem sobre as obras o mesmo que estas podem sobre aqueles: desestabilizar seus pressupostos e borrar fronteiras. A obra de arte que existe e resiste é aquela capaz de olhar para esse período de violência, incorporar as vozes silenciadas e silenciadoras presentes ali, e tentar nomear, renarrar e intervir no campo do simbólico.

\section{Referências}

AGAMBEN, Giorgio. Homo sacer: o poder soberano e a vida nua I. Trad. Henri que Burigo. Belo Horizonte: Editora UFMG, 2010.

BUNTINX, Gustavo. Lava la bandera: el Colectivo Sociedad Civil y el derroca miento cultural de la dictadura en el Perú. E-misférica, New York, nำ3.1, junho 2006. Disponível em: http://hemisphericinstitute.org/journal/3.1/eng/en31_ pg_buntinx.html. Acesso em: 15 abr. 2016.

DIDI-HUBERMAN, Georges. Sobrevivência dos vagalumes. Trad. Vera Casa Nova e Márcia Arbex. Belo Horizonte: Editora UFMG, 2011.

DIEGUEZ CABALLERO, Ileana. Cenários liminares (teatralidades, performances e política). Trad. Luis Alberto Alonso e Angela Reis. Uberlândia: EDUFU, 2011.

DIEGUEZ CABALLERO, lleana. Evocações espectrais. A propósito de Sin título - técnica mixta. In Sin título - técnica mixta. Direção: Miguel Rubio Zapata. Trad. Carla Dameane P. de Souza. 2012. Prospecto. 
JELIN, Elizabeth. Los trabajos de la memoria. Lima: Instituto de Estudios Perua nos, 2012.

PERU. Hatun Willakuy. Versión abreviada del informe final de la Comisión de la Verdad y Reconciliación - Perú. Lima, diciembre de 2003.

RANCIÈRE, Jacques. A partilha do sensível. São Paulo: Editora 34, 2009.

RUBIO ZAPATA, Miguel. El cuerpo ausente. Lima: Yuyachkani, 2006.

VICH, Victor. El canibal es el otro - violencia y cultura en el Perú contemporá neo. Lima: Instituto de Estudios Peruanos, 2002.

Poéticas del duelo - ensayos sobre arte, memoria y violencia política en el Perú. Lima: Instituto de Estudios Peruanos, 2015.

Recebido em: 26/04/2016 Aprovado em: 02/07/2016 